Arch Virol (1998) 143: 1941-1948

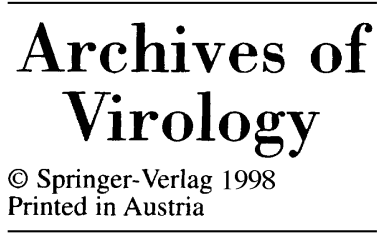

\title{
Characterization of haemagglutinin-esterase protein (HE) of murine corona virus DVIM by monoclonal antibodies
}

\author{
H. Kasai*, E. Morita*, K. Hatakeyama, and K. Sugiyama \\ Department of Biology, Faculty of Science, Hirosaki University, Hirosaki, Japan
}

Accepted May 14, 1998

Summary. We analyzed the characteristics of seven monoclonal antibodies (mAbs) raised against purified HE (hemagglutinin-esterase) glycoprotein of the murine coronavirus DVIM (diarrhea virus of infant mice). Immunocrossreaction of these mAbs with JHM and/or MHV-S suggest that antigenic epitopes of HE of DVIM are similar to those of JHM and/or MHV-S. Four mAbs (1b4, 3a28, $4 \mathrm{c} 19,10 \mathrm{~b} 7)$, designated as group A mAbs, strongly inhibited both HA and AE activities. On the other hand, three mAbs (5a3, 6a6, 13a4), referred to as group B, had a comparatively weak HA inhibition activity. These results indicate that the antigenic epitopes of this glycoprotein can be classified into at least two groups and that the functional sites of HA and AE activities are similar but not identical. Neutralizing activity was shown in group A mAbs exclusively, suggesting that the ratio of $\mathrm{HA}$ and/or AE activities may play important roles in the cell fusion activity of DVIM-infected cells.

\section{Introduction}

Coronaviruses are enveloped viruses containing a single-stranded RNA genome of positive polarity [3-5]. Murine coronavirus MHV-DVIM is an enteropathogenic coronavirus causing severe diarrhea in newborn mice [6-8]. As described in a previous report [8], by treatment of DVIM with the non-ionic detergent NP-40 we isolated the HE protein, which carries the functional sites for both acetylesterase (AE) and the haemagglutination (HA) activities. The contribution of these activities to infection by MHV-DVIM is not yet known, nor is their relation to the antigenic epitopes. To know the antigenic properties of HE, several monoclonal antibodies (mAbs) raised against the purified protein were established and used

\footnotetext{
*Present address: Department of Microbiology and Immunology, Medical School, Tohoku University, Sendai, Japan.
} 
to characterize the $\mathrm{HE}$ protein. In the present report, we provide evidence that the functional sites for AE and HA activities have separate locations on the HE protein. Furthermore, mAbs that inhibit AE activity also suppress the ability of DVIM to cause cell fusion from within.

\section{Materials and methods}

Virus and cells

Murine coronavirus MHV-DVIM was grown in DBT cells using Eagle's MEM supplemented with $7 \%$ newborn calf serum (GIBCO) and 3\% tryptose phosphate broth (DIFCO). The virus was purified as described previously $[6,7]$.

\section{Acetylesterase (AE) assay and acetylesterase inhibition (AEI) assay}

The AE activity was determined according to the methods described by Vlasak et al. $[9,10]$. Purified virions dissolved in $50 \mu \mathrm{l}$ of PBS $(1 \mu \mathrm{g} / \mu \mathrm{l})$ were reacted with $50 \mu \mathrm{l}$ of $\mathrm{mAbs}(0.15 \mu \mathrm{g} / \mu \mathrm{l})$ (dilution rate $10^{-1}$ to $\left.10^{-3}\right)$ for $1 \mathrm{~h}$ at room temperature. After addition of $50 \mu \mathrm{l}$ of esterase substrate ( $\mathrm{mM}$ p-nitrophenilacetate: dissolved in $1 \%$ acetonitril), the solution was incubated for $10 \mathrm{~min}$ at $37^{\circ} \mathrm{C}$, and hydrolysis of the substrate was monitored at $\mathrm{OD}_{400 \mathrm{~nm}}$ with a spectrophotometer (HITACHI 150-20). The inhibitory effect was expressed as the percentage against a blank that contained PBS instead of the virus.

\section{Haemagglutination (HA) and haemagglutination inhibition (HAI) assay}

HA assays were performed in V-shaped microtiter plates as described previously [6] using $0.5 \%$ (vol/vol) erythrocytes of Balb/c mice (in Dulbecco's PBS, pH 7) supplemented with $0.3 \%$ bovine serum albumin (BSA: Sigma). The titer was recorded as the reciprocal value of the highest dilution causing a detectable HA reaction. HAI assays were also carried out in microtiter plates. Aliquots of $25 \mu \mathrm{l}$ of purified virions (4-HAU) were reacted with $25 \mu \mathrm{l}$ of serial two-fold dilutions of mAbs in a V plate. After $1 \mathrm{~h}$ at $4{ }^{\circ} \mathrm{C}, 50 \mu \mathrm{l}$ of $0.5 \%(\mathrm{v} / \mathrm{v})$ erythrocytes were added. After incubation for $12 \mathrm{~h}$ at $4{ }^{\circ} \mathrm{C}$, the $\mathrm{HI}$ titer was recorded as the reciprocal value of the highest dilution causing a detectable inhibitory effect.

\section{Preparation of monoclonal antibodies(mAbs)}

The preparation method was the same as that described in a previous paper [8].

\section{Neutralization test}

Neutralization tests by mAbs were carried out by a semimicro reduction assay [1,2]. The virus $\left(0.1 \mathrm{TCID}{ }_{50} / \mathrm{ml}\right)$ was mixed with diluted antibodies, incubated for $1 \mathrm{~h}$ at $4{ }^{\circ} \mathrm{C}$, and plated onto 24-well plates. After adsorption for $1 \mathrm{~h}$ at room temperature, the plates were washed with PBS ( $\mathrm{pH} 7.4$ ), and the culture medium was added to the cells. The neutralization titer was expressed as the highest antibody dilution that prevented virus infection $\left(\mathrm{TCID}_{50} / \mathrm{ml}\right.$ ). The ratio of fusion formation was calculated from the number of nuclei in which the cells formed a syncytium.

\section{Results}

Preparation of $m A$ bs against HE protein of DVIM

Since gp69 was identified as the HE glycoprotein of DVIM [8], we attempted to characterize the antigenic sites of this glycoprotein. We obtained seven clones 
Table 1. Antigenic analysis of mAbs of the HE protein

\begin{tabular}{|c|c|c|c|c|c|c|}
\hline & Antigen site & & Subgroup & mAbs & Isotype & $\begin{array}{l}\text { Neutralization } \\
\text { titer } \mathrm{CPE}^{\mathrm{c}}\end{array}$ \\
\hline group & $\mathrm{HAI}^{\mathrm{a}}$ & $\mathrm{AEI}^{\mathrm{b}}$ & & & & 12 h p.i. \\
\hline \multirow[t]{4}{*}{ A } & $(\geqq 1024)++++$ & $(80 \%)++++$ & A-1 & $4 \mathrm{c} 19$ & $\lg G_{1} / \kappa$ & $320^{-1}$ \\
\hline & $(\geqq 1024)++++$ & $(55 \%)++++$ & A-1 & $10 \mathrm{~b} 7$ & $\operatorname{lgG}_{1} / \kappa$ & $320^{-1}$ \\
\hline & $(64)++$ & $(85 \%)++++$ & A-2 & $3 a 28$ & $\operatorname{lgG}_{1} / \kappa$ & $80^{-1}$ \\
\hline & $(32)++$ & $(85 \%)++++$ & A-2 & $1 \mathrm{~b} 4$ & $\operatorname{lgG}_{1} / \kappa$ & $40^{-1}$ \\
\hline \multirow[t]{3}{*}{ B } & $(4)+$ & $(86 \%)++++$ & B-1 & $5 \mathrm{a} 3$ & $\lg G_{1} / \kappa$ & +++ \\
\hline & $(\leqq 2)+$ & $(12 \%)+$ & B-2 & $6 a 6$ & $\lg G_{1} / \kappa$ & +++ \\
\hline & $(8)+$ & $(11 \%)+$ & B-2 & $13 \mathrm{a} 4$ & $\operatorname{lgG}_{1} / \kappa$ & +++ \\
\hline
\end{tabular}

${ }^{\mathrm{a}} \mathrm{HAI}$ was determined as described in Materials and methods

${ }^{\mathrm{b}} \mathrm{AEI}$ was determined at the dilution of 1:500 of $\mathrm{mABs}$

${ }^{\mathrm{c}}$ Neutralization activity was expressed as the reciprocal of the highest dilution of mAb that showed fusogenic CPE at $12 \mathrm{~h}$ post infection. CPE (syncytium) $(+++)$ developed overall in the cell sheet

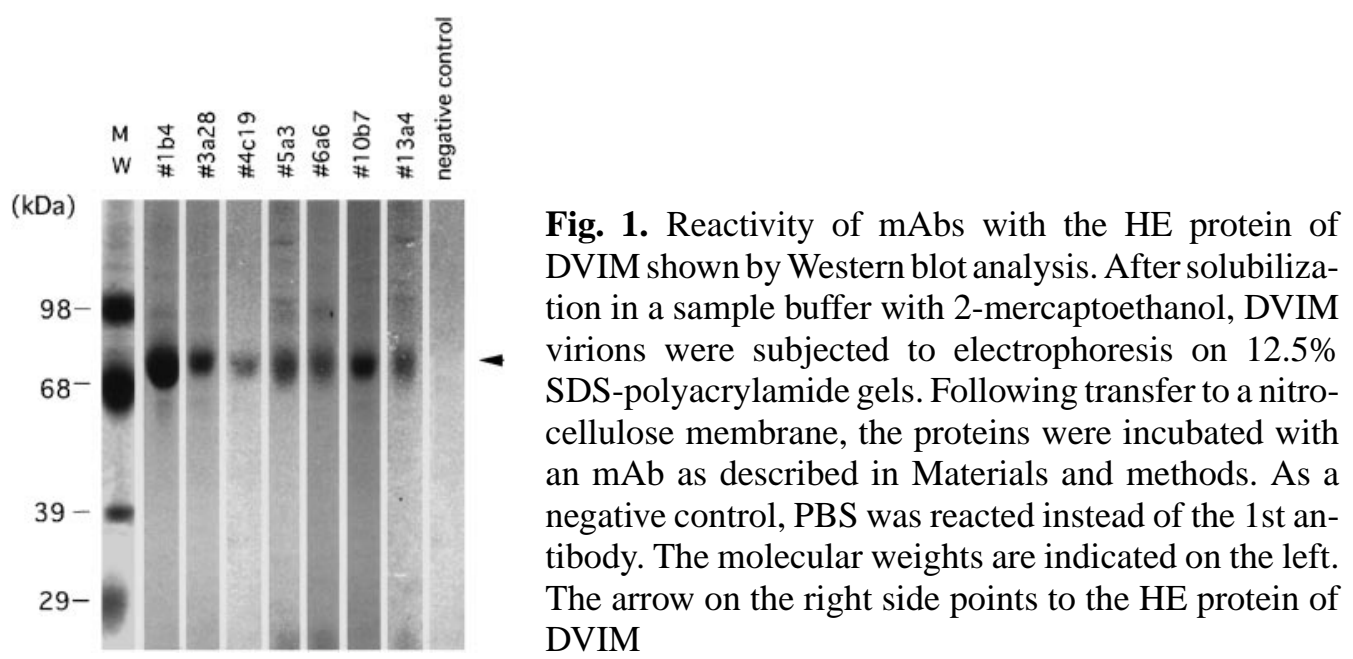

of mAbs $(4 \mathrm{c} 19,10 \mathrm{~b} 7,13 \mathrm{a} 4,1 \mathrm{~b} 4,3 \mathrm{a} 28,5 \mathrm{a} 3$ and $6 \mathrm{a} 6)$ directed against the HE glycoprotein. All of them were identified as belonging to the $\operatorname{IgG}(1 / \kappa)$ isotype (Table 1) and reacted with the polypeptide of the gp69 kDa of DVIM in Western blot analysis, indicating that they recognize an epitope that exists on this glycoprotein (Fig. 1). These mAbs were also examined for the crossreactivity with other strains of MHV as well as with influenza $\mathrm{C}$ virus, which also contains an acetylesterase, by Western blot analysis. As shown in Fig. 2, six mAbs recognized a major $69 \mathrm{kDa}$ protein of MHV-JHM but no crossreactivity was observed with 


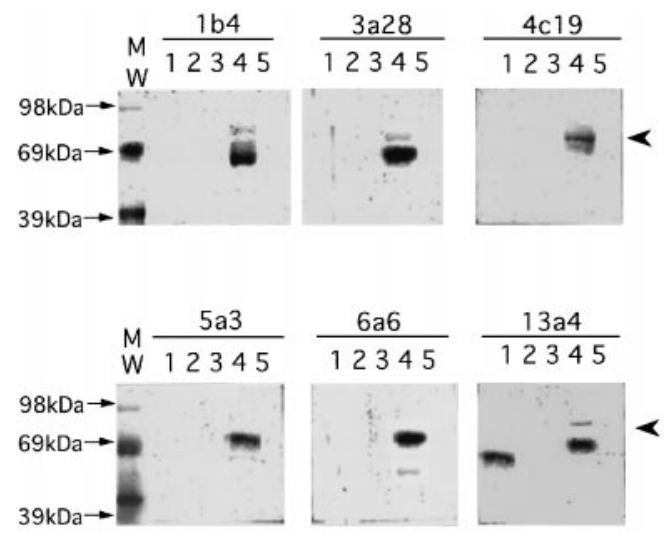

Fig. 2. Analysis of the mAbs for crossreactivity with MHVs or influenza $\mathrm{C}$ virus. The following strains were used: $1 \mathrm{MHV}-\mathrm{S}$, 2 MHV-2, 3 MHV-3, 4 MHV-4, 5 influenza C/Miyagi/77. The position of M.W. markers is shown on the left. The arrow on the right indicates the major band of HE (approximately M.W. $69 \mathrm{kDa})$

MHV-2, MHV-3 and influenza C/Miyagi/77 virus (Fig. 2). However, mAb 13a4 also reacted with gp65 of MHV-S. These results indicate that the HE glycoprotein of DVIM has antigenic similarity with that of MHV-JHM and to some extent also with MHV-S.

\section{Inhibition of biological activities by $m A b s$}

To determine the biological properties of these mAbs, we examined their inhibitory activities against acetylesterase, hemagglutination, and fusion (from within) activites, respectively. Inhibition of acetylesterase (AEI) was analyzed by determining the effect of the mAbs on the ability of the viral enzyme to release p-nitrophenol from p-nitrophenylacetate. As shown in Table 1, five mAbs (4c19, 10b7, 3a28, $1 \mathrm{~b} 4$ and 5a3) showed high AEI titers (55-86\%). Two mAbs (6a6 and 13a4) were found to have low levels (10-12\%) of AEI titer. High hemagglutination inhibition (HAI) titers $(>512)$ were measured with three mAbs $(10 \mathrm{~b} 7$ and $4 \mathrm{c} 19)$. With two mAbs (1b4 and 3a28), intermediate values (32-64) were obtained. The mAbs (6a6, $5 \mathrm{a} 3$ and 13a4) had low HAI titers $(<4 \sim 8)$ (Table 1). These data suggest that these mAbs were classifiable into at least two groups: group A $(4 \mathrm{c} 19,10 \mathrm{~b} 7$ and $1 \mathrm{~b} 4)$ that has a high titer to both activities and an intermediate titer to the HA activity, and group B (5a3, 6a6 and 13a4) that has low titers to both activities (Fig. 5 and Table 1). To determine the correlations between $\mathrm{AE}$ and $\mathrm{HA}$ active sites, the inhibitory effects against HA and AE activities by DFP were also tested. Inhibitory effects were shown only in the AE activity and not in the HA activity (data not shown). These results suggests that HA and AE active sites that exist on the HE glycoprotein of DVIM are separated etiologically.

We examined the cytopathic effect of mAbs with respect to the formation of syncytia in DVIM-infected cells. Fusion was evident at $12 \mathrm{~h}$ postinfection (p.i.). The mAbs 5a3, 6a6, and 13a4 were unable to prevent this cytopathic effects, and no syncytia formation was observed at $12 \mathrm{~h}$ p.i. when the virus was treated with mAbs 1b4, 3a28 and 4c19 prior to infection (Fig. 3). It should be noted, however, that these antibodies did not completely neutralize DVIM. They only delayed 

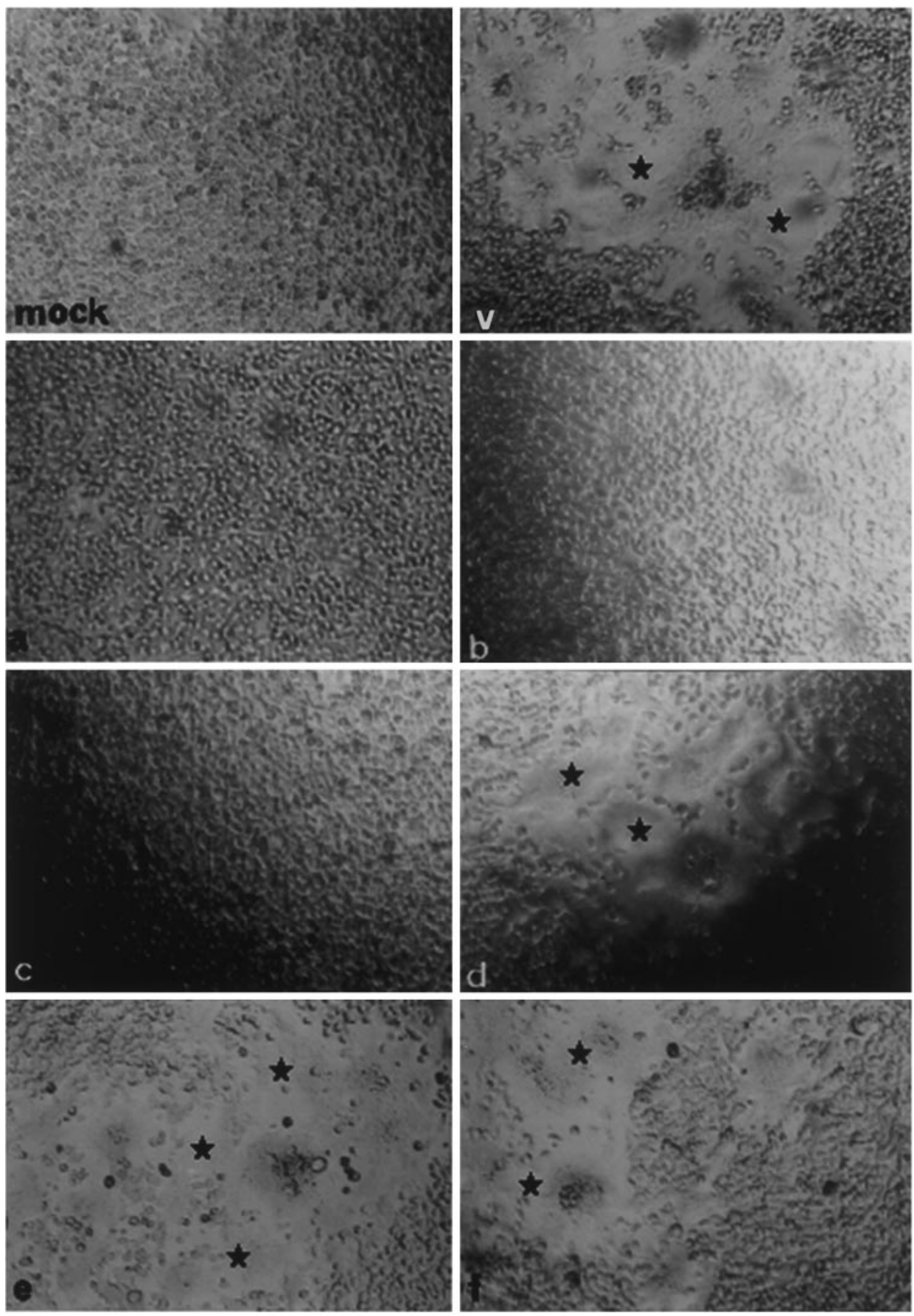

Fig. 3. Inhibitory effects of mAbs on DVIM-infected DBT cells. DBT cell-sheets were treated with $(0.1 \mathrm{TCID} / 50)$ virus-antibody mixtures for $1 \mathrm{~h}$ at $4{ }^{\circ} \mathrm{C}$, and plated onto 24 -well plates. After washing with PBS, the cells were fed with culture medium and photographed at 12 h p.i. Mock Cell control, v virus control, a 1b4, b 3a28, c 4c 19, d 5a3, e 6a6, f 13a4. Cytopathic effect (fusion from within) is shown by asteriks 


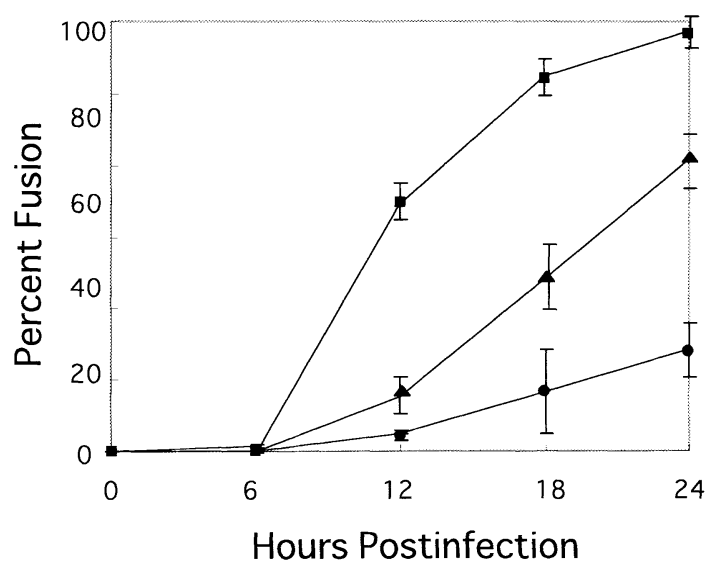

Fig. 4. Inhibitory effect of mAbs on syncytium formation (cytopathogenic effect) of DVIM (at approx. m.o.i. at 1.0) after treatment with diluted mAbs (diluted $\times 4)$. - $\mathbf{\Delta}-$ mAb13a4, - mAb4c19, - - - PBS+virus

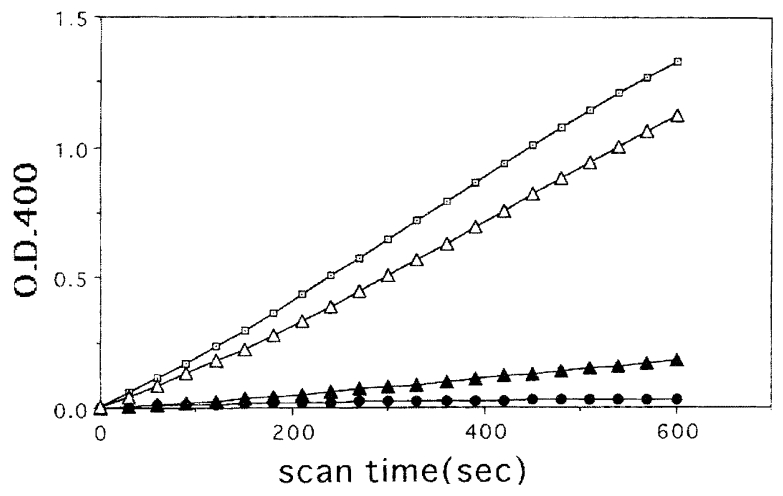

Fig. 5. Inhibition of acetylesterase by mAbs. The inhibitory effect of AE was assayed as described in Materials and methods. Hydrolysis of substrates (p-nitrophenilacetate) was monitored at $\mathrm{OD}_{400 \mathrm{~nm}}$ with a spectrophotometer. - $\mathbf{\Delta}-\mathrm{mAb} 4 \mathrm{c} 19,10 \mathrm{~b} 7,3 \mathrm{a} 28,1 \mathrm{~b} 4,-\triangle-5 \mathrm{a} 3$, $6 \mathrm{a} 6$ 13a4. The representative reaction of these was demonstrated. $-\square$ - Reaction of purified virus $(100 \mu \mathrm{g} / \mathrm{ml})$--O- Inhibition with DFP

virus cell fusion activity, because syncytia were observed by $24 \mathrm{~h}$ p.i. (Fig. 4). These data indicate the existence of a neutralization factor on the HE glycoprotein of DVIM.

\section{Discussion}

The role of the HE protein in virus infection is unclear [3-5]. For some viruses, such as bovine coronavirus and human coronavirus OC43, this protein appears to be essential, because no variants or mutants that lack this protein have been found $[3,5]$. The esterase activity of HE has been suggested to play a role either in virus entry or in virus release [3-5]. Though MHV is serologically related, it differs from the other viruses of this serogroup in several aspects. While the bovine and human counterparts use 9-O-acetylated sialic acid on the plasma membrane for binding to cells, biliary glycoprotein serves as a receptor for MHV $[1,9,10]$. In addition only some strains of MHV contain an HE-protein, while others lack such 
a protein $[3,5]$. Even strains like DVIM that contain an HE-protein and thus are able to release the $\mathrm{O}$-acetyl groups from $\mathrm{N}$-acetyl-9-O-acetylneuraminid acid use biliary glycoprotein as a receptor [2]. Thus, the importance of the HE-protein for MHV is not known.

To obtain more information about the HE protein, we raised antibodies to this protein and analyzed their effect on the biological activities of HE. With respect to inhibition of hemagglutination activity and acetylesterase activity, there were antibodies that had a high titer to both activities or a high titer to one activity and an intermediate titer to the other activity. Two antibodies had low titers to both activities. From these results, we conclude that there are several epitopes present on the HE protein. The data also indicate that the functional sites of the hemagglutination and acetylesterase activities are similar but not identical. None of the antibodies completely neutralized DVIM. However, some of the antibodies delayed the onset of syncytium formation and the cytopathic affect. All these antibodies had high AEI activities and high or intermediate HAI activities. The antibodies that had low titers to both activities did not delay the fusion of infected cells. Therefore, a functional acetylesterase activity and/or hemagglutination activity appear to be necessary for optimal infection by DVIM. Further investigation is needed to determine the exact role of the HE protein. The antibodies described here should be helpful in this respect.

\section{Acknowledgement}

We wish to H. Ebina of Hirosaki University, Faculty of Science for his helpful assistance of this work.

\section{References}

1. Boyle JF, Weismiller DG, Holmes KV (1987) Genetic resistance to mouse hepatitis virus correlates with absence of virus-binding activity on target tissues. J Virol 61: 185-189

2. Gagneten S, Goutg O, Dubois-Dalco M, Rottier P, Rossen J, Holmes KV (1995) Interaction of mouse hepatitis virus (MHV) spike glycoprotein with receptor glycoprotein MHVR is required for infection with an MHV strain that express the hemagglutininesterase glycoprotein. J Virol 69: 889-895

3. Holmes K (1990) Coronaviridae and replication. In: Fields BN, Knipe DM (eds) Virology, 2nd ed. Raven Press, New York, pp 842-856

4. Siddel S, Wege H, Ter Meulen V (1982) The structure and replication of coronaviruses. Curr Top Microbiol Immunol 99: 131-163

5. Sturman LS, Holmes KV (1983) The molecular biology of coronavirus. Adv Virus Res 28: $35-112$

6. Sugiyama K, Amano Y (1980) Hemagglutination and structural polypeptides of a new coronavirus associated with diarrhea in infant mice. Arch Virol 66: 95-105

7. Sugiyama K, Ishikawa R, Fukuhara N (1986) Structural polypeptides of the murine coronavirus DVIM. Arch Virol 89: 245-254

8. Sugiyama K, Kasai M, Kato S, Kasai H, Hatakeyama K (1998) Haemagglutinin-esterase protein (HE) of murine corona virus: DVIM. Arch Virol 143: 1523-1 534

9. Vlasak R, Luytjes W, Spaan W, Palese P (1988) Human and bovine coronaviruses recognize sialic acid-containing receptors similar to those of influenza $\mathrm{C}$ viruses. Proc Natl Acad Sci USA 85: 4 526-4 529 
10. Vlasak R, Luytjes W, Leider J, Spaan W, Palese P (1988) The E3 protein of bovine coronavirus a receptor-destroying enzyme with acetylesterase activity. J Virol 62: 4 6864690

Authors' address: Dr. K. Sugiyama, Department of Biology, Faculty of Science, Hirosaki University, Hirosaki 036, Japan.

Received February 11, 1998 